\title{
Construções identitárias de estudantes de farmácia no trote universitário: questões de gênero e sexualidade
}

\author{
Vera Helena Ferraz de Siqueira ${ }^{*}$, Marina Cardoso Gondin da Fonseca ${ }^{* *}$, \\ Márcia Bastos de Sä ${ }^{* * *}$, Ana Cristina Moreira Lima
}

Resumo: Este artigo, embasado nos estudos culturais e em noções pós-estruturalistas sobre identidade, poder, sexualidade e gênero, apresenta estudo empírico baseado na ideia de que em espaços náo formais da universidade ocorrem processos importantes de construção identitária. O contexto do estudo foi uma universidade pública, e os dados foram obtidos principalmente pela observação de atividades do trote universitário e por entrevistas com estudantes do curso de Farmácia. Evidenciamos como o ritual do trote universitário, por meio de várias atividades, constitui tecnologia contemporânea de poder. Identificamos situaçóes no trote em que sexismo, significados homofóbicos e assédio moral prevalecem, sempre travestidos como brincadeiras. Significados sobre a sexualidade estão imbricados com questóes de gênero e de consumo: os corpos são expostos e assujeitados em processos que excluem o que foge da norma e reforçam identidades hegemônicas. Esses discursos e práticas, construtores de conhecimentos e significados sociais, deveriam ser considerados pela universidade.

Palavras-chave: formação profissional; sexualidade; gênero; trote universitário; identidades.

Pharmacy students identity construction through hazing: gender and sexuality issues

Abstract: This article, based upon the idea that in non formal University spaces important processes of identity construction take place, presents an empirical study conducted in consonance with notions of the cultural studies, in relation to the issues of identity, power, sexuality and gender. The context of the study was a public university and the data was obtained mainly through the observation of hazing activities and interviews conducted with Pharmacy students. We have evidenced ways through which hazing constitutes a modern power technology. Situations were identified in which sexism, homophobe meanings and moral harassment prevail, always represented as jokes. Meanings on sexuality were found

* Professora do Núcleo de Tecnologia Educacional para a Saúde (Nutes) da Universidade Federal do Rio de Janeiro (UFRJ), Brasil. Apoio CNPq. verahfs@yahoo.com.br

* Licencianda em Educação Física na UFRJ e bolsista de iniciação científica do CNPq, Brasil. marinagondin@hotmail.com

**** Doutorandas no Programa de Pós-Graduação em Educação em Ciências e Saúde do Nutes/ UFRJ, Brasil.marciabsa@hotmail.com, anamolina@ig.com.br. 
intertwined with gender and consumerism aspects: the bodies were exposed and subjected to processes which exclude what was seen as "not normal", reinforcing the hegemonic identity. Such discourses and practices build knowledge and social meanings and should receive greater attention by the University.

Key words: educational background; sexuality; gender; hazing; identities.

Para entender a formação profissional não basta compreender como conhecimentos formais - aqueles que se encontram nos livros ou nos ensinamentos dos(as) professores(as) - são transmitidos e apropriados pelos(as) alunos(as). O conhecimento deriva também do que Foucault denominou "saberes", que se relacionam às práticas cotidianas, às opinióes públicas, às normas, às regras, à moralidade, etc. (Foucault, 1994, apud Scheurich; Mckenzie, 2005) e a aprendizagens sobre o que se pode aspirar na vida, os papéis a serem cumpridos como homens e mulheres na sociedade, e as formas de exercer a cidadania.

A formação desses saberes está intimamente vinculada a relaçôes de poder, situando-se em circunstâncias e contextos socioculturais específicos, como nas universidades, entendidas como instituiçóes modernas que estabelecem parâmetros para as açóes dos sujeitos por meio de seus currículos, horários e rotinas. Sáo esquemas que delimitam um conjunto de regras em relação à produção acadêmica, aos métodos de ensino e aos comportamentos de alunos(as) e professores(as), e que materializam práticas discursivas. Como ensinou Foucault:

As práticas discursivas não são pura e simplesmente modos de fabricação de discursos. Ganham corpo em conjuntos técnicos, em instituiçóes, em esquemas de comportamentos, em tipos de transmissão e de difusão, em formas pedagógicas, que ao mesmo temo as impóem e as mantêm. (1997, p. 23).

Um dos discursos que marcam a modernidade refere-se à identificação da universidade como um dos lugares privilegiados para a formação da cidadania, tendo como um de seus projetos centrais a transmissão de uma visão de mundo coerente com o jovem, enfatizando a racionalidade, o progresso e a autonomia individual (Veiga Neto, 2002). Sob a lógica da modernidade, há um progressivo ajuste dos indivíduos ao sistema de regras socialmente instituídas; entretanto, a linearidade desse discurso é evidenciada quando se considera a trama complexa e desigual de experiências que tem lugar nessas instituiçóes, permeadas por procedimentos, técnicas e alvos que conformam modalidades de poder, "borrando" as previsóes e as certezas. Assim, ao penetrarmos "a rede constitutiva das relaçóes sociais que individualizam os sujeitos" para detectar "como funcionam as coisas no nível do processo de sujeiçâa” (Foucault, 1979, p.182), verificamos que os eventos não se enquadram bem nessa lógica da ordem e da previsibilidade. É o caso das relaçóes 
estabelecidas entre os(as) alunos(as) em alguns contextos não formais, do modo como agem em eventos que, embora não apoiados pela universidade, são aceitos, como é o caso do trote universitário.

O cotidiano na universidade concretiza-se nos espaços de socialização fora das demarcações do currículo formal, como em festas, grupos de estudo, trotes e encontros religiosos, e estes são contextos produtivos para indagaçóes sobre construçôes identitárias mediadas por relaçóes de poder. Nesses contextos em que os(as) alunos(as) se posicionam, engajam-se em açóes e assumem valores, suas identidades são construídas; como aponta Hall (1997, p. 26), as identidades e as diferenças sáo ocasionadas por um conjunto especial de sentimentos, histórias e experiências, ou seja, são formadas culturalmente. Elas são construídas ao longo de discursos, estando em constante processo de mudança e transformação. As instituiçóes educativas devem ser entendidas como espaços onde, por meio de embates e relaçóes de poder, as identidades são produzidas e se produzem e onde se corporifica o conjunto de todas as experiências cognitivas e afetivas proporcionadas a estudantes. Como expóe Louro:

[...] a escola e o currículo estáo longe de ser meros reflexos das condiçôes sociais. A partir de múltiplas práticas cotidianas e banais, a partir de gestos e expressôes pouco perceptíveis, pelo silêncio, pelo ocultamento ou pela fala, constroem-se, no espaço propriamente escolar, lugares e destinos sociais, produzem-se identidades de gênero e sexuais, identidades de classe e de etnia, marcadas pela diferenciação e pela hierarquia (2004, p. 91).

Conforme mencionado em Siqueira e Rocha (2008), os processos de exclusão, a rejeição ao Outro, considerado inferior e diferente, certamente não são novos; entretanto, vários autores vêm apontando a responsabilidade de acentuar a rejeição do "diferente", causada por certas condiçôes colocadas na chamada "modernidade tardia" a partir de determinantes maiores de diversas ordens. Por exemplo: nas instituiçôes de ensino superior, grupos marginalizados, favorecidos por recentes políticas de inclusão, estão ingressando nas universidades brasileiras; e, em um nível micro, a identificação de certas características no(a) outro(a) constitui, de certa forma, uma ameaça à identidade do sujeito. Entre importantes catalisadores dos processos de exclusão estão o gênero, a sexualidade, a raça/etnia e a classe social. Acreditamos que processos de subjetivação de estudantes e professores diante de tais deslocamentos repercutem nos papéis que cumprem como cidadáos, educadores e futuros profissionais.

Assumimos também que as formas pelas quais atualmente está se dando a construção das identidades e das diferenças estão estreitamente relacionadas à questão da cidadania. Canclini (1997) aponta os direitos à diferença como uma 
dimensão central tomada na América Latina nos últimos tempos para entender a cidadania - e não mais apenas os direitos à igualdade, como anteriormente. Os direitos são importantes - mais do que como valores abstratos - como algo que se constrói e muda em relação a práticas e discursos. A cidadania e os direitos não falam unicamente da estrutura formal de uma sociedade; além disso, indicam o estado da luta pelo reconhecimento dos outros como "sujeitos de interesses válidos, valores pertinentes e demandas legítimas" (Canclini, 1997, p. 36). A ideia de que uma teoria da cidadania náo deve considerar todos os indivíduos como sujeitos dos mesmos direitos e obrigaçôes, apenas com interesses diversos, é defendida por vários pensadores contemporâneos, que desafiam a noção essencializante da cidadania, negam toda a perspectiva de homogeneização e convidam-nos a analisar as formaçôes e as experiências sociais a partir da complexa configuração da realidade social: "O problema não são só os interesses diversos, mas as diferentes identidades de classe, sexo, raça, etnicidade, preferência sexual e muitas outras diferenças nas percepçóes, preferências e experiências do ator social" (Torres, 2001, p. 275).

É possível afirmar que os sujeitos são discursivamente produzidos, o que vai contra a noção de sua naturalizaçáo, tão contestada nos últimos tempos pelo campo dos estudos culturais, por feministas, pós-estruturalistas, entre outros. O discurso está ligado ao poder, na medida em que age como uma forma de disciplina, subjetivando uma dada forma de pensar, de agir, de se posicionar. Múltiplos discursos - médicos, pedagógicos e políticos, entre outros - competem na constituição da identidade dos sujeitos como homens, mulheres, cidadãos, estudantes, futuros profissionais, etc.

Apoiado nesses pressupostos, o presente artigo tem como foco as construçóes de identidades relacionadas às experiências do trote universitário, em uma universidade pública, evidenciadas especialmente em discursos e práticas de estudantes de Farmácia, com ênfase em suas marcas de gênero e sexualidade. Discutimos também as relaçóes dessas representaçôes com algumas semióticas presentes no espaço físico do Centro de Ciências da universidade em que ocorreu o estudo onde estáo localizadas salas de aula, centros acadêmicos e espaços de convivência - por meio das quais proliferam apelos relacionados à sexualidade e ao consumo, responsáveis pela construção de saberes.

Este artigo, um recorte pesquisa mais ampla, apoia-se em estudo empírico, cujos dados foram obtidos no período de julho de 2009 a março de 2010 por meio de entrevistas, observaçóes e visitas a sites de relacionamento dos estudantes da Faculdade de Farmácia de uma universidade pública da região sudeste. Foram realizadas 11 entrevistas semiestruturadas com calouros(as), veteranos(as) da comissão de trote e outros(as) veteranos(as) representantes de entidades estudantis, como o Centro Acadêmico e a Atlética da Farmácia, por acreditarmos que o pertencimento a esses agrupamentos poderia influir nos discursos produzidos. Entendendo que "a 
informação a respeito das mulheres é necessariamente informação sobre os homens, que um implica no estudo do outro" (Scott, 1990, p. 3), tivemos o cuidado de entrevistar tanto jovens do sexo feminino (5) como do sexo masculino (7); destes, sete veteranos(as), três calouros(as) e duas ex-estudantes do curso de Farmácia. Foi utilizado o critério de "saturação teórica" para determinar a suspensão de inclusão de novos sujeitos, ou seja, paramos de fazer entrevistas quando consideramos que os dados obtidos passaram a apresentar certa repetiçáo (Angrosino, 2005).

Os resultados evidenciam que um conjunto de técnicas e regras estrutura o trote universitário e que os sujeitos calouros(as) e veteranos(as) produzem, questionam e se enquadram nessa estrutura a partir de relaçóes de poder. Relaçóes estas móveis e instáveis, constituídas a partir de um processo de normalização - que incide principalmente sobre os corpos dos(as) jovens - cuja referência importante é a lógica binária, que estabelece a heterossexualidade como norma e o investimento nos corpos como superfícies de inscrição de marcas de gênero.

\section{Identidades, diferenças e poder}

Como fio constitutivo das relaçóes sociais está o poder, que permeia a formação identitária, quando, por exemplo, os indivíduos participam de interaçóes sociais que tendem a lembrá-los(as) quais lugares de sujeito devem ser ocupados para serem aceitos, para náo destoarem do que foi estabelecido como a "forma natural de ser". As identidades só se definem por meio de um processo de produção da diferença. Ou, poderíamos dizer que a percepção do(a) outro(a) se dá em estreita relação com a construção identitária. A redução do(a) outro(a) a um atributo coletivo efetua-se na base do que Goffman (1988) chamou um estigma: cor da pele, maneira de falar, maneira de se vestir, gênero, etc. Atribuir, assim, ao outro certa categoria social considerada como sua essência - quando se trata, na verdade, de uma questão social e cultural - constitui uma estratégia para valorizar-se e desvalorizar-se, afirmar sua cultura, rejeitando o outro por causa de sua natureza. Essas características frouxas, pouco específicas, atuam como marcas simbólicas essencialistas, ocultando o caráter discursivo e construído das questóes de raça, etnia, gênero e orientação sexual. Exemplificamos usando a crítica estabelecida por Stuart Hall em torno da unificação da identidade nacional em torno da raça:

[...] contrariamente à crença generalizada, a raça não é uma categoria biológica ou genética que tenha qualquer validade científica. Há diferentes tipos e variedades, mas eles estâo tão largamente dispersos no interior do que chamamos de "raças" quanto entre uma "raça" e outra. A diferença genética - o último refúgio das ideologias racistas - não pode ser usada para distinguir um povo do outro. A raça é uma categoria discursiva e não uma categoria biológica. (2000a, p. 62-63). 
É apenas por meio da relação com o Outro, da relação com aquilo que não é, que a identidade pode ser construída. A identidade hegemônica não faria sentido sem aquilo que é exterior a ela, que corresponde a sua diferença. As marcas da construção da identidade hegemônica - ela é forjada a exemplo do que ocorre com as identidades subalternas - desaparecem, e ela surge apenas como a identidade, e não como uma dentre a multiplicidade de identidades existentes.

Pois, se uma identidade consegue afirmar-se é apenas por meio da repressão daquilo que a ameaça. A constituição de uma identidade está sempre baseada no ato de excluir algo e de estabelecer uma violenta hierarquia entre os dois polos resultantes - homem/mulher, etc. Aquilo que é peculiar ao segundo termo é, assim, reduzido - em oposição à essencialidade do primeiro - à função de um acidente. Ocorre a mesma coisa com a relação negro/branco, na qual o branco é, obviamente, equivalente a "ser humano". "Mulher" e "negro" são assim, "marcas" (isto é, termos marcados) em contraste com os termos não marcados "homem" e "branco". (Laclau, apud Hall, 2000b, p. 110).

Reconhecer a não essencialidade das identidades, ou seja, seu caráter construído e discursivo, constitui pressuposto de nosso estudo, que se volta ao entendimento das construçóes identitárias em contextos na universidade onde estudantes, professores e outros atores interagem. Assumimos que hierarquias de gênero, etnia/ raça, etc. são construídas situacionalmente na relação mantida entre os indivíduos, nos vários espaços institucionais.

É a partir de um sistema de marcação de diferenças e organização do poder que diferenciaçôes como de raça/etnia ou de sexo/ gênero devem ser contempladas. A desnaturalização desses elementos abre lugar para a valorização de relaçôes sociais no entendimento das diferenças entre os indivíduos, as quais implicam, conforme postula Scott

no que tange às relaçóes de gênero, em símbolos culturalmente disponíveis que evocam representaçóes simbólicas [...], em conceitos normativos que póem em evidência as interpretaçóes do sentido dos símbolos, que se esforçam para limitar e conter suas possibilidades metafóricas [...], e também na identidade subjetiva (Scott, 1990, p.14-15).

Dessa forma, evidencia-se a multiplicidade de correlaçóes de forças a partir das quais se deve pensar o efeito desses elementos nas relaçóes sociais e institucionais. Entendemos que tais marcaçóes de diferença (raça/etnia, sexo/gênero, etc.) são construídas de forma relacional e devem ser contempladas de forma articulada. Processos de exclusão dão-se a partir de demarcaçôes, que estabelecem fronteiras e impedem o diálogo entre as diferentes culturas e grupos. Identidades e diferenças são construídas no interior de uma sociedade e culturas específicas. Como 
vêm apontando os estudos culturais, o conceito de centro é relacionado à noção de universalidade, em oposição às novas identidades excêntricas, que se situam às margens e trazem as marcas das particularidades e da diversidade. Um conjunto de normas regula os comportamentos, atitudes e valores em cada cultura, sendo importante elemento da ordem social. Eixos de representaçóes binárias, como masculino/feminino, negro/branco, capaz/incapaz e inteligente/ignorante, veiculados por um conjunto de símbolos e significados transmitidos pela linguagem e outras semióticas, incidem na construção identitária dos indivíduos.

\section{Consumismo, gênero e sexualidade}

Celebraçóes, eventos científicos ou esportivos promovidos pelos estudantes frequentemente refletem uma lógica mercantilista, como no caso do trote, um ritual tradicional entre os estudantes, em que os(as) calouros(as) são submetidos(as) a uma série de provaçóes pelos(as) veteranos(as). A lógica mercantil, característica da sociedade maior, concretiza-se também no espaço físico onde convivem diariamente: o prédio do Centro de Ciências.

Nos corredores do prédio, proliferam semióticas materializadas por cartazes e faixas afixados nas paredes. Interpelaçóes como "Muito sexo e prazer", "chope liberado" ou "cerveja a preço de custo" servem como atrativo para as atividades sociais e festas, coordenadas em cada curso por uma comissáo de festas. Notam-se também stands que anunciam as vantagens de alguns planos privados de saúde sobre outros planos; instituições bancárias expóem suas condições vantajosas, especiais para estudantes, stands vendem uma diversidade de quinquilharias, etc. Em tal contexto, os (as) estudantes também anunciam e vendem suas festas, esquentadas por muito álcool e sexo, como no caso da "Biolorgia" e "Farmálcool".

Significados sobre a sexualidade estão relacionados com o consumismo, que, como lembra Bauman, é um tipo de arranjo social resultante do rearranjo de desejos humanos rotineiros, "transformando-os na principal força propulsora e operativa da sociedade" (2008, p. 41). Os apelos de consumo convidam os indivíduos a se envolverem em certas açóes; eles interpelam os membros da sociedade como consumidores e avaliam-nos de acordo com a adequaçáo e a prontidáo de suas respostas a tal chamado (Bauman, 2008, p. 71).

É nesse contexto que tem lugar o trote, prática tradicional, que tem o poder como fio constitutivo, como ocorre em todas as relaçôes sociais. Já foram objeto de nossos estudos os trotes e outras manifestaçôes estudantis de diferentes áreas da saúde: Biologia, Enfermagem e Medicina. É importante ter em vista que, na universidade, lidamos com diferentes subculturas que, ao mesmo tempo que compartilham um conjunto de códigos e regras que se referem à sociedade maior da qual fazem parte, também contam com conceitos, valores e códigos específicos 
de suas subculturas. Cecil Helman, médico antropólogo, faz referência a várias subculturas profissionais, tais como os grupos de médicos e enfermeiros, cada qual "com seus próprios conceitos, regras e organização social":

Embora cada subcultura seja desenvolvida a partir de uma cultura maior, e compartilhe muitos de seus conceitos e valores, esta também possui feiçôes características únicas. Os estudantes das profissôes [...] também sofrem uma espécie de endoculturação ao adquirirem gradualmente a cultura da carreira escolhida. Nesse processo, adquirem uma perspectiva na vida diferente daquela de quem está fora desse contexto profissional. (2003, p. 23-24). O antropólogo continua sua exposição chamando atenção para o fato de que muitas das divisóes sociais e dos preconceitos da sociedade maior se refletem nas culturas profissionais, o que - no caso do(a) profissional de saúde - pode interferir na atenção à saúde e na sua comunicaçấo com a comunidade.

A sexualidade ocupa centralidade no trote, que é uma atividade investida por regras e cujo planejamento entre os(as) estudantes de Farmácia ocorre com semanas de antecedência; uma coordenaçáo determina os horários e as atividades, que são postados no Orkut, com informações sobre os locais de encontro, sobre o que levar, como se vestir, etc. Uma das atividades mais populares do trote é o pedágio, no qual os(as) calouros(as) são instruídos(as) para pedir dinheiro nas ruas e cada um(a) deles(as) deve recolher uma quantia estipulada pelo comando dos veteranos.

A atividade do pedágio envolve um considerável planejamento, pois ocorre ao mesmo tempo em vários bairros da cidade. Os corpos dos(as) calouros(as) são pintados com diferentes símbolos que frequentemente transmitem mensagens sexuais. Algumas calouras usam pouca roupa e/ou roupas provocantes, como no caso de uma menina da Farmácia que - pintada de vaca - exibia as palavras à venda escritas na barriga, com uma flecha apontando para seu órgáo sexual. Enquanto os(as) calouros(as) cumprem sua tarefa, os(as) transeuntes fazem insinuaçóes, os veículos param, ressoam assobios, etc. Futuramente, todo o dinheiro arrecadado será utilizado na produçáo de uma chopada, que é o ponto culminante do trote. Nessa função de coletar dinheiro, surgiu o reconhecimento da maior eficiência das mulheres, conforme captado em uma conversa no Messenger, na qual elas são investidas de significados sexuais e mercantis por apresentarem um desempenho superior ao dos homens: bom que você é mulher, homem pega um terço disso.

Por outro lado, os corpos masculinos receberam frequentemente pinturas de super-heróis, sempre ressaltando tronco e membros superiores; era como uma norma: homem deve tirar a camisa para ser pintado, o que pode ser interpretado 
como um reforço à ideia da força física como uma qualidade puramente masculina, reafirmando assim sua suposta superioridade. No caso das mulheres, a maioria das pinturas foi investida de um significado sexual, chamando a atenção para peitos e pernas, naturalizando o corpo da mulher como objeto de prazer do homem.

Notou-se que, para alcançar bom desempenho, as mulheres muitas vezes passavam por situações de assujeitamento, recebendo cantadas, buzinadas, etc. Nesses processos, os corpos, os gestos e os desejos são permeados pelo poder e tornam-se objeto de saber sobre o papel da mulher na sociedade, sobre o uso dos corpos, etc. Entretanto, essas jovens são também o centro de transmissão do poder, que "passa por elas"; em outras palavras, náo estáo em condição apenas de sofrer, mas também de exercer o poder (Foucault, 2003, p.183).

Os(as) veteranos(as) comandam as atividades em estilo militar: observam hierarquias, fazem ameaças e levam a cabo puniçóes, como foi também observado em estudo de Almeida Jr. e Queda (2006) em universidades paulistas. Sançóes normalizadoras, julgamentos e represálias são estabelecidos em relação ao comportamento esperado por parte dos calouros. Não participar do trote ou se opor a ele pode resultar em processos de exclusão, como não ser bem-vindo(a) no Centro Acadêmico, e/ou ser tachado de estranho.

No prédio do mencionado Centro, várias outras atividades ocorrem comandadas pelos(as) veteranos(as), como ordenar aos rapazes para agirem como mulheres, participarem de danças eróticas ou fazer com que os calouros carreguem cartazes com autodescriçóes, por exemplo, questionando sua masculinidade e seu desempenho sexual.

Outra atividade é colocar os(as) calouros(as) numa fila e ordenar que um(a) coma um pedaço de banana e que passe para a boca do(a) outro(a) estudante, até que as bocas de dois estudantes se encontrem. Essa atividade, repetida usando cenouras e balas, acontece entre rapazes e moças e também entre moças e moças. Neste último caso, nota-se muita agitação quando as meninas se beijam.

Alguns(mas) estudantes se referem ao trote como humilhante, perigoso e insuportável. Nas palavras de uma liderança do Centro Acadêmico da Faculdade de Farmácia, ao ser questionado sobre sua opinião a respeito do trote:

Então, o trote ele é horrivel né? O trote, ele é opressor. Tomei o trote e o meu trote, vou te falar que pra mim foi um dos piores. Assim, eu, particularmente eu, como eu passei bem, bem, eu passei no vestibular em $2^{\circ}$ então... eu tomei um trote pesado assim, fui bem humilhado, bem humilhado. E eu na realidade assim, o trote ele é um, é uma opressão que um certo número de estudantes faz para com outros. Opressão essa vazia, baseada em nada, baseada em uma superioridade fictícia que não existe, e essa opressão tem fins lucrativos, ela é produto de um sistema 
lucrativo. Porque ela quer gerar um dinheiro inicial, pra gerar um evento maior que vai gerar mais dinheiro e esse evento maior, e esse dinheiro, parte dele vai pro bolso de quem organiza esse evento e de quem oprime. Ou seja, o trote serve ao capital. Eeles usam a desculpa de que o trote serve pra integração.

Vários(as) dos(as) estudantes, principalmente aqueles(as) que estão mais diretamente envolvidos(as) com sua organização, referem-se ao trote como muito divertido, uma importante oportunidade de integração entre os(as) alunos(as) e de fazer amigos(as), uma instância de socialização. A desconstrução dessa ideia, bastante naturalizada entre os(as) estudantes, foi feita pelo estudante acima mencionado:

Apesar do trote gerar uma certa integração, porém ele não serve a ela, entendeu? Porque a integração, ela vai gerar inevitavelmente. E mesmo assim o trote, ele não é a ferramenta para se integrar porque existem outras ferramentas melhores do que o trote, como a gente faz... (e menciona atividade realizada pelo CA da Farmácia antes da ocorrência do trote).

O ritual é repetido todos os anos, e aqueles(as) estudantes que foram humilhados(as) se tornam líderes no próximo ano, o que evidencia a mobilidade do poder. Uma estudante de Farmácia expóe o trote nos seguintes termos:

Eu acho que o trote é sempre uma vingança, seja lá boa ou ruim, porque não adianta, você sofreu o trote, po, o que a gente mais falava enquanto tinha o elefantinho [atividade do trote] era: "cara, meus calouros vão dar 30 voltas, ali no pátio do CCS, pra sofrer o que a gente sofreu, pra ter dor na coluna e tomar remédio por que teve dor na coluna".

Significados homofóbicos também foram frequentes. Os(as) calouros(as) são testados(as) sobre a sua sexualidade, tendo que parodiar homossexuais de diferentes maneiras: dançando, ajoelhando-se para pegar uma cenoura posicionada entre as pernas de outro calouro com a boca, etc. Segue o relato de uma atividade que ocorreu no primeiro dia do trote da farmácia; o aluno menciona-a como aquela que para ele foi a pior, em que em frente a uma audiência teve que se assumir como uma bicha enrustida, um lixo (os dois termos aparecem relacionados em sua fala).

É, geralmente assim, no início da apresentação, no caso eu fui o primeiro na... que tinha que fazer. Eu fui o primeiro, ai tinha que ler um, ai no caso eu tinha que ler um pedido de desculpas pra ele, escreveram um negócio humilhante (com ênfase) que tinha... Nossa, muita humilhaçấo! E, aí eu subi lá em cima, li o negócio pra todo mundo, sabe? Tipo, assim: "desculpa meu supremo veterano por ter sido tão idiota..." Sabe? Eu sou uma 
bicha enrustida, não sei o que... Sabe? Um negócio bem assim, humilhante! "Vou fazer de tudo para ajudar na faculdade porque eu sou um lixo, e nãnãnã...” Várias coisas, desse tipo assim.

Para a maioria dos(as) entrevistados(as), o curso de Farmácia é tido por alunos(as) de outros cursos do CCS como um curso no qual só tem viado. Os homens homossexuais são motivo de chacota, e eles são aceitos como pessoas excêntricas e engraçadas. Nas palavras de um aluno da farmácia:

A pessoa tipo, questão se for homossexual, na Farmácia tem assim um número bastante grande de homossexuais. Se tu pöe numa turma entra, sei lá, 17, 18 homens, po, desses ai pelo menos uns 5 são homossexuais. Po é 1/3 né? Sempre rola assim umas piadas, as pessoas falando: "po, fulano", "ahh, aquele maluco mó boiolão, num sei o que lá, tinha que ser viado e tal" E eu não tenho problema com isso não. Eu me enturmo muito bem. Pelo menos nunca tive problema nenhum com eles, sabe? Tem uns que tu acha também, são muito engraçados, (risos) morro de rir, eu acho que só, é... A participação deles na farmácia só ajuda a tornar o curso mais engraça... Mais divertido que são muito engraçados, né?

Neste ponto, trazemos brevemente a noção foucaultiana de normalização, por contribuir para o entendimento das performances verbais e não verbais dos(as) alunos(as), tendo em vista a insidiosa presença de discursos que enquadram desvios das normas e definem qual seria uma perspectiva legítima de vida para os sujeitos.

Para Foucault, no século XIX, o velho sistema penal (cujas penalidades incidiam através de torturas sobre o corpo) é substituído por um sistema em que novas táticas de punição, "mais sutis, mais veladas e despojadas de ostentação" (1987, p.12), deslocam-se do corpo para a alma: "À expiação que tripudia sobre o corpo deve suceder um castigo que atue, profundamente, sobre o coraçáo, o intelecto, a vontade, as disposiçôes" (p.18). E o alvo final deste novo aparato jurídico "não é apenas um julgamento de culpa... Carrega uma avaliação de normalidade e uma prescrição técnica para uma possível normalização" (p. 20-21) que se aplica na sociedade como um todo. Na visão do filósofo, um efeito do novo regime penal não é punir o criminoso, mas sim a "ordenação", o que é um recurso importante para o sucesso do poder disciplinar na modernidade.

Nesse sentido, os discursos normalizam, instauram saberes ao imporem imagens binárias de sexo, da qual a heterossexualidade enquanto prática normativa e naturalizada é constitutiva. Como mostra Foucault, as práticas discursivas da atualidade "[...] se caracterizam pelo recorte de um campo de objetos, pela definição de uma perspectiva legítima para o sujeito do conhecimento". (Foucault, 1997, p. 11). 
Quando, no futuro próximo, os(as) oprimidos(as) se tornam opressores(as), chega sua vez de humilhar os(as) outros(as) como foram humilhados(as), e o ciclo perpetua-se. Aqueles(as) submetidos(as) às brincadeiras não mostram resistência efetiva, pois reagir poderia resultar em ser considerado(a) diferente. No caso das mulheres, resistir poderia implicar em afetar sua feminilidade, uma vez que a construçáo do corpo feminino em nossa sociedade é relacionada à exibição do corpo e à ostentação sexual para a apreciação masculina. Professores(as), diretores(as) e toda instituição, em geral, mostram reaçóes tímidas e/ou se omitem.

Siqueira e Rocha (2008), com apoio em Giroux (2003), argumentam que é possível também supor que não faz parte do repertório desses(as) alunos e alunas uma linguagem de crítica e de possibilidade. $\mathrm{O}$ mencionado autor sugere que, para os(as) estudantes universitários(as) irem além das questôes do entendimento até um envolvimento com as dimensôes mais profundas que os(as) tornam cúmplices de ideologias opressoras, eles(as) devem ser orientados(as) "para abordar e formular estratégias de transformação pelas quais suas crenças individualizadas possam ser articuladas com discursos públicos mais amplos, que aumentem os imperativos da vida pública democrática" (Giroux, p. 121). Esses(as) estudantes são produzidos nessas práticas e aprendem como lidar com a ambivalência, como aceitar e reproduzir situaçóes nas quais o sexismo, o assédio moral e a falta de ética prevalecem. E suas identidades são formadas "por esse conjunto especial de circunstâncias, sentimentos e experiências” (Hall, 1997, p. 26), que são, em resumo, formadas culturalmente. Elas são multiplamente construídas e se relacionam às práticas discursivas correntes, estando constantemente em processo de mudança e transformação.

Como observado em Siqueira (2006), tais práticas se constituem como acréscimo discursivo, fazendo circular na sociedade novas narrativas de gênero e de sexualidade. Contrariamente à teoria vigente sobre a repressão do sexo, Foucault (2008) expõe uma aparelhagem que nos últimos séculos põe em funcionamento discursos estabelecidos a partir de diferentes pontos de vista para obter efeitos de poder sobre os sujeitos. Discursos sobre o sexo passaram a proliferar a partir do século XVIII, através da incitaçâo promovida pelas instituiçôes escolares, familiares, pela medicina e, sobretudo, pela pastoral cristá. Este é o marco histórico na sociedade ocidental para que tudo passe a ser dito e detalhado.

Noçóes de Foucault, como a dos efeitos do poder na subjetivação do sujeito moderno e sua incidência sobre o corpo, influenciaram teorias feministas. Foucault (2008) evidenciou como a identidade é produto de uma relação de poder exercida sobre corpos, movimentos e desejos. Tal noção, ao situar o corpo e a sexualidade como construçôes culturais, corre em direção oposta à visão essencialista das diferenças concebidas em torno da matriz genital/biológica predominante até os anos 1960, quando teóricas feministas criaram a noção de gênero como categoria analítica da divisão sexuada do mundo. Essa formulação desloca o eixo do enten- 
dimento das relaçóes, sobretudo, para aspectos da cultura, de forma coerente com a visão de descentramento do indivíduo.

\section{Considerações finais}

Evidenciamos aqui algumas estratégias que investem os corpos de mulheres e homens. No primeiro caso, obscurecem a multiplicidade do ser-mulher, por meio de processos de opressão que criam e marcam o feminino em suas delimitaçóes sociais. A exibiçáo do corpo feminino para satisfazer o prazer masculino reduz esse corpo a um sexo, amálgama que, como aponta Swain (s.d.), resulta em práticas de subordinação, reproduzindo discursos fundadores, como os de filosofia e teologia, de que o homem tem um sexo e a mulher é um sexo. Vimos também que um conjunto de regras alinhadas com a regra da heterossexualidade estabelece definiçóes em torno da forma única e correta para viver a sexualidade.

É pressuposto que alunos(as) e professores(as) se constituam como sujeitos a partir desses processos, os quais são histórica e culturalmente estabelecidos e ocorrem em contextos de interação específicos da universidade. Em outras palavras, pelas relaçôes mútuas mantidas nesses diferentes contextos, com base em uma rede de relaçōes com outros professores, alunos, agrupamentos, etc., utilizando uma variedade de gêneros (conversas, manifestaçóes, palestras, etc.), os indivíduos formam e transformam suas identidades e constituem-se como sujeitos que acreditam e/ou rejeitam certas ideias, conferem um ou outro significado à docência ou ao exercício dos papéis do alunado e de seu futuro profissional, etc. Uma vez que o poder é relacional, é embate, é produtivo, e ocorre entre os indivíduos a partir de uma pluralidade de relaçóes de forças que atravessam todo o corpo social (Foucault, 2003, p. 148), essa complexa relaçáo de forças traz a possibilidade da constituiçáo de novos modos de sensibilidade, de outros modos de relação consigo mesmo e com o outro, enfim, novos modos de subjetivaçáo.

Para Giroux, os(as) estudantes universitários(as) deveriam ser orientados(as) "para abordar e formular estratégias de transformação pelas quais suas crenças individualizadas possam ser articuladas com discursos públicos mais amplos, que aumentem os imperativos da vida pública democrática" (Giroux, 2003, p. 121). A nosso ver, isso permitiria que encaminhassem reivindicaçōes de condições de igualdade, a exemplo do que vem sendo efetuado por diversos movimentos sociais, como no caso do feminismo.

A questão, bastante complexa, de como as instituiçóes educativas podem contribuir para que os sujeitos efetuem um trabalho "de si sobre si", instrumentalizandoos(as) para uma visualizaçáo de outras "formas de ser" e de viver e para que possam efetuar "o rompimento com padróes sociais que prescrevem uma forma única de associação e afetividade entre as pessoas" (Miskolci, 2006, p. 690), permanece um 
desafio. Ao mesmo tempo que reconhecemos as diferentes culturas dos cursos e das profissóes, temos como pressuposto que, dadas as especificidades da história e da cultura institucional das universidades, ocorrem variaçóes importantes entre as atitudes, os comportamentos e os posicionamentos de alunos e professores, influenciados pela cultura institucional. Nesse sentido, parece importante desenvolver o mesmo estudo em outras áreas da saúde e em outras universidades.

Linhas divisórias, lugares de sujeito, hierarquias foram evidenciados nos discursos e nas práticas dos(as) estudantes; elas são reconstruídas constantemente nos microespaços. Como sublinha Foucault: "Deve-se supor que as relaçóes de força múltiplas que se formam e atuam nos aparelhos de produção, as famílias, os grupos restritos, as instituiçôes servem de suporte a grandes efeitos de clivagem que percorrem o conjunto do corpo social" (Foucault, 2003, p.124).

\section{Referências bibliográficas}

ALMEIDA JR., A. R.; QUEDA, O. Universidade preconceitos e trote. São Paulo: Hucitec, 2006. ANGROSINO, M. V. Recontextualizing observation. Ethnography, Pedagogy, and the Prospects of a Progressive Political Agenda. In: DENZIN, N.; LINCOLN, Y. (Ed). 3 ed. The Sage Handbook of Qualitative Research. US: Sage Publications, 2005.

BAUMAN, Z. Vida para consumo. A transformaçáo das pessoas em mercadoria. Rio de Janeiro: Zahar, 2008.

CANCLINI, N. G. Culturas híbridas: estratégias para entrar e sair da Modernidade. São Paulo: Ed. da USP, 1997.

FOUCAULT, M. Vigiar e punir. nascimento da prisão. Petrópolis: Vozes, 1987.

FOUCAULT, M. História da sexualidade 1. A vontade de saber. Rio de Janeiro: Graal, 2008.

FOUCAULT, M. Resumo dos cursos do College de France (1970-1982)/ Michel Foucault. Rio de Janeiro: Zahar, 1997.

FOUCAULT, M. Microfisica do poder. 18 ed. Rio de Janeiro: Graal, 1979.

GIROUX, H.. Atos impuros. A prática política dos estudos culturais. Porto Alegre, RS: Artmed, 2003.

GOFFMAN, E. Estigma: notas sobre a manipulação da identidade deteriorada. 4 ed. Rio de Janeiro: Guanabara, 1988.

HALL, S. A centralidade da cultura: notas sobre as revoluçóes culturais do nosso tempo. Educação e Realidade, v. 2, n. 22, p. 16-46, jul./dez. 1997.

HALL, S. A identidade cultural na pós-modernidade. Rio de Janeiro, DP\&A, 2000a.

HALL, S. Quem precisa da identidade? In: SILVA, T. T.; HALL, S.; WOODWARD, K. (Org.). Identidade e diferença. A perspectiva dos estudos culturais. Petrópolis, Rio de Janeiro: Vozes, 2000b. 
HELMAN, C.G. Cultura, saúde e doença. Porto Alegre: Artmed, 2003.

LOURO, G. L. Um corpo estranho: ensaios sobre sexualidade e teoria queer. Belo Horizonte: Autêntica, 2004.

MISKOLCI, R. Corpos elétricos: do assujeitamento à estética da existência. Revista Estudos Feministas, Florianópolis, v. 14, n. 3, p. 681-693, set./dez. 2006.

SCHEURICK, J. J.; MCKENZIE, K. B. Foucault's Methodologies, Archaeology and Genealogy. In: DENZIN, N.; LINCOLN, Y. (Ed.). The Sage Handbook of Qualitative Research. 3 ed. US: Sage Publications, 2005.

SCOTT, J. Gênero: uma categoria útil para análise histórica. Revista Educação e Realidade. Porto Alegre, v. 16, n. 2, p. 5-22, jul./dez., 1990.

SIQUEIRA, V. H. F. Sexualidade, gênero e educação: a subjetivação de mulheres pelo cinema. Educaçâo e Realidade, v. 31 n. 1., p. 127-143, 2006.

SIQUEIRA, V. H. F.; ROCHA, G. W. F. A construção de diferenças de gênero entre estudantes de medicina em espaços não formais da universidade. Cadernos Pagu, Campinas v. 30, p. 231-268, 2008.

SWAIN, T. N. Quem tem medo de Foucault? Feminismo, corpo e sexualidade. Espaço Michel Foucault. Disponível em: <www.filoesco.unb.br/foucault>. Acesso em: 20 nov. 2010.

TORRES, C. A.. Democracia, educação e multiculturalismo. Dilemas da cidadania em um mundo globalizado. Petrópolis, RJ: Vozes, 2001.

VEIGA NETO, A. De geometrias, currículo e diferenças. Educação e Sociedade. Campinas, v. 23, n. 79, p. 163-186, ago. 2002.

Recebido em 01 de abril de 2011 e aprovado em 21 de julho de 2011. 
